\title{
Pengaruh Attraction, Accessibillity, Amenity, Ancillary Terhadap Kepuasan Generasi Millenial Berkunjung ke Tempat Wisata
}

\author{
Stella Alvianna1, Ryan Gerry Patalo², Syarif Hidayatullah*3, Ike Kusdyah Rachmawati ${ }^{4}$ \\ Program Diploma Kepariwisataan Universitas Merdeka Malang 1 \\ Program Diploma Keuangan dan Perbankan Universitas Merdeka Malang ${ }^{2}$ \\ Fakultas Ekonomi dan Bisnis Universitas Merdeka Malang ${ }^{3}$ \\ Fakultas Ekonomi Institut Teknologi dan Bisnis Asia Malang ${ }^{4}$ \\ *Email: syarif_ok@yahoo.com
}

\begin{abstract}
Indonesia has various regions with potential tourism attractions that can attract tourists, one of them is Malang City, where Malang City is also known as one of the main tourist destinations in Indonesia. This study illustrates the influence of the components of tourism products consisting of attractions, access, amenities and ancillary to the decision of visiting tourists, especially millennial generation in the Tlogowaru mask tourism village of Malang. Topeng Village which is one of the tourist destinations in the form of thematic villages with the theme of Malangan Mask that has been around since the year 2016. The population of this study is all students of the Unmer Tourism Tourism Program Malang who entered the millennial age (aged between 1534 years) with a sample of 60 people based on their characteristics visited Malangan mask village. Data analysis used multiple linear regression and hypothesis testing. The results of the research show that attraction and ancillary have a positive and significant effect on customer satisfaction. This shows the perception of what tourists get and what tourists feel can have a positive impact and also the presence of officers on guard, the presence of security posts and the existence of a tourist information center that continues to be maintained and improved, also has a positive impact on tourist attractions.
\end{abstract}

Keywords: Attraction, Accessibility, Amenity, Ancillary, and Tourism Satisfaction.

\begin{abstract}
Abstrak
Indonesia memiliki berbagai wilayah dengan potensi daya tarik pariwisata yang dapat menarik wisatawan salah satunya yaitu Kota Malang, yang dimana Kota Malang juga dikenal sebagai salah satu tujuan wisata utama di Indonesia. Penelitian ini menggambarkan pengaruh dari Komponen produk pariwisata yang terdiri dari Aktraksi, akses, amenitas dan ancillary terhadap keputusan berkunjung wisatawan khususnya generasi milenial di Kampung wisata topeng Tlogowaru Kota Malang. Kampung Topeng yang merupakan salah satu destinasi wisata berupa kampung tematik bertemakan Topeng Malangan yang sudah ada sejak taun 2016. Populasi penelitian ini adalah semua mahasiswa Program Diploma Kepariwisataan Unmer Malang yang masuk usia millennial (usia antara 15-34 tahun) dengan sampel sejumlah 60 orang berdasarkan karakteristik mereka pernah mengunjungi kampung topeng Malangan. Analisis data digunakan regresi linear berganda dan uji hipotesis. Hasil penelitian meninjukan atraksi dan ancillary berpengaruh positif dan signifikan terhadap kepuasan pelanggan. Hal ini menunjukan persepsi apa yang wisatawan dapatkan dan apa yang wisatawan rasakan dapat berdampak positif dan juga terdapatnya petugas yang berjaga, terdapatnya pos keamanan serta terdapatnya pusat informasi wisata yang terus di pelihara dan ditingkatkan, juga memberikan dampak positif bagi tempat wisata.
\end{abstract}

Kata Kunci: Atraksi, Akses, Aminitas, Ancillary, dan Kepuasan Wisatawan.

\section{A. PENDAHULUAN}

Indonesia memiliki berbagai wilayah dengan potensi daya tarik pariwisata yang dapat menarik wisatawan salah satunya yaitu Kota Malang. Kota Malang merupakan salah satu dari 3 wilayah yang disebut Malang Raya yaitu Kota Malang, Kota Batu dan Kabupaten Malang. Kota Malang dikenal sebagai salah satu pusat kota pelajar di Provinsi Jawa Timur karena memiliki berbagai perguruan tinggi, selain 
menjadi kota pelajar kawasan Malang Raya dikenal juga sebagai salah satu tujuan wisata utama di Indonesia, salah satu desinasi wisata yang dapat dikunjungi yaitu Wisata Kampung Topeng Tlogowaru yang berada di daerah Tlogowaru, Kecamatan Kedungkandang Kota Malang, dan generasi millennial menjadi daya Tarik jika dihubungkan dengan penelitian ini.

Wisata Kampung Topeng Tlogowaru berlokasi di Dusun Baran, Tlogowaru, Kecamatan Kedungkandang, Kota Malang (Badan Pusat Statistik Kota Malang, 2016). Wisata Kampung Topeng Tlogowaru ini berada di wilayah dataran yang cukup tinggi dan terdapat banyak pepohonan serta tanaman hias lainnya yang menjadikan suasana di kampung wisata topeng ini terasa sejuk dan asri. Di area Wisata Kampung Topeng Tlogowaru terdapat topeng Panji Asmoro Bangun dan Dewi Sekartaji yang berukuran besar. Keduanya adalah tokoh raja dan ratu yang bijak dalam cerita rakyat Malang. suatu daerah tujuan wisata harus didukung oleh 4 (empat) komponen utama dalam pariwisata atau biasanya dikenal dengan istilah " $4 \mathrm{~A}$ " yang harus dimiliki oleh sebuah daya tarik wisata yaitu Attraction (atraksi wisata), Accesibility (aksesibilitas), Amenity (amenitas), dan Ancillary services (pelayanan tambahan). Semakin baik suatu objek wisata maka kepuasan wisatawan juga akan terbentuk, dan akan semakin dikenal oleh wisatawan yg lain apabila mendapatkan rekomendasi yang positif dan untuk mendapatkan eksistensi dari kampung wisata topeng malangan.

Wisatawan millennial menjadi suatu fenomena yang sangat menarik, dan generasi ini terbentuk dengan gaya hidup pup culture (S. Alvianna \& Hidayatullah, 2020; Stella Alvianna, 2017b). didukung dengan perkembangan teknologi yang sangat pesat, segala macam bentuk informasi dengan mudah didapat, serta berkembangnya media social sangat mudah bagi wisatawan untuk menentukan atau memilih suatu destinasi yang akan dituju. Dan hal ini tidak terlepas dari generasi yg ada saat ini atau biasa disebut generasi millennial yang mampu untuk beradaptasi dan mengakses perkembagan teknologi yang ada. (Hidayatullah, Rachmawati, Aristanto, Waris, \& Patalo, 2020). Penelitian lain tentang kepuasan disampaikan oleh (Soebiyantoro, 2010) Penelitian ini mempersentasikan bagaimana dampak ketersediaan sarana dan prasarana, sarana transportasi dalam menyediakan kebutuhan-kebutuhan wisatawan dalam menikmati wisata hiburan yang tersedia maupun wisata atraksi yang ditampilkan dalam memberikan kepuasan bagi wisatawan. Selanjutnya (Hidayatullah, Rachmawati, \& Khouroh, 2017) mengatakan pengembangan pariwisata perlu melibatkan masyarakat sekitar atau kelompok yang ada sehingga atraksi yang ada akan lebih variatif. Dari penelitian terdahulu yang ada penelitian ini berusaha untuk memberikan masukan untuk kampung topeng dari sisi informasi yang pada akhirnya dapat digunakan sebagai pengambilan keputusan pengembangan wisata kampung topeng. Adapun tujuan dari penelitian ini : untuk mengetahui pengaruh variabel Attraction (atraksi wisata), Accesibility (aksesibilitas), Amenity (amenitas), dan Ancillary services (pelayanan tambahan) terhadap kepuasan kaum millennial berkunjung ke kampung topeng.

\section{TINJAUAN LITERATUR \\ Generasi Milenial}

Generasi millennial adalah sebutan bagi kelompok usia yang tumbuh di tahun 2000an, dan adanya istilah atau sebutan ini karena mereka peka terhadap teknologi yang terus meningkat. Seperti penggunaan internet dan aktif dalam menggunakan social media, merupakan sebutan bagi generasi millennial. (Garth, 2015; Hidayatullah, Waris, \& Devianti, 2018).

\section{Destinasi wisata}

Daya tarik tempat tujuan wisata merupakan motivasi utama bagi pengunjung untuk melakukan kunjungan wisata (Pendit, 2002) Ada pula yang berpendapat bahwa kerangka pengembangan destinasi pariwisata mengandung tujuan yang sama yang mencakup unsur-unsur seperti attaraction, accessbilities, amenity, dan ancillary (Scott, Cooper, \& Baggio, 2008) 


\section{Kepuasan Wisatawan}

Suatu ungkapan atau perasaan yang muncul akibat dari suatu penilaian terhadap suatu objek (Kotler, 1990). Suatu ungkapan terhadap suatu objek yang dapat memberikan manfaat yang baik bagi (Stella Alvianna, 2017a; Tang, 2014)

\section{B. METODE PENELITIAN}

Penelitian deskriptif kuantitatif digunakan dalam penelitian ini dengan melihat gambaran suatu fenomena yang muncul. Adapun variable yang diambil dan menjadi variable bebas adalah (Atraction, Accessibility, Amenity, dan Ancillary), Variabel terikat (kepuasan pengunjung). Proses pengumpulan data dari hasil survey lokasi, open koesioner, dan telaah pustaka. Wisata Kampung Topeng Tlogowaru yang berlokasi di Desa Tlogowaru, Kecamatan Kedungkandang, Kota Malang, Jawa Timur. Populasi penelitian ini adalah semua mahasiswa Program Diploma Kepariwisataan Unmer Malang yang masuk usia millennial (usia antara 15-34 tahun) dengan sampel sejumlah 60 orang berdasarkan karakteristik mereka pernah mengunjungi kampung topeng Malangan. Analisis data digunakan regresi linear berganda dan uji hipotesis. Dan dapat dilihat pada konsep di gambar 1 :

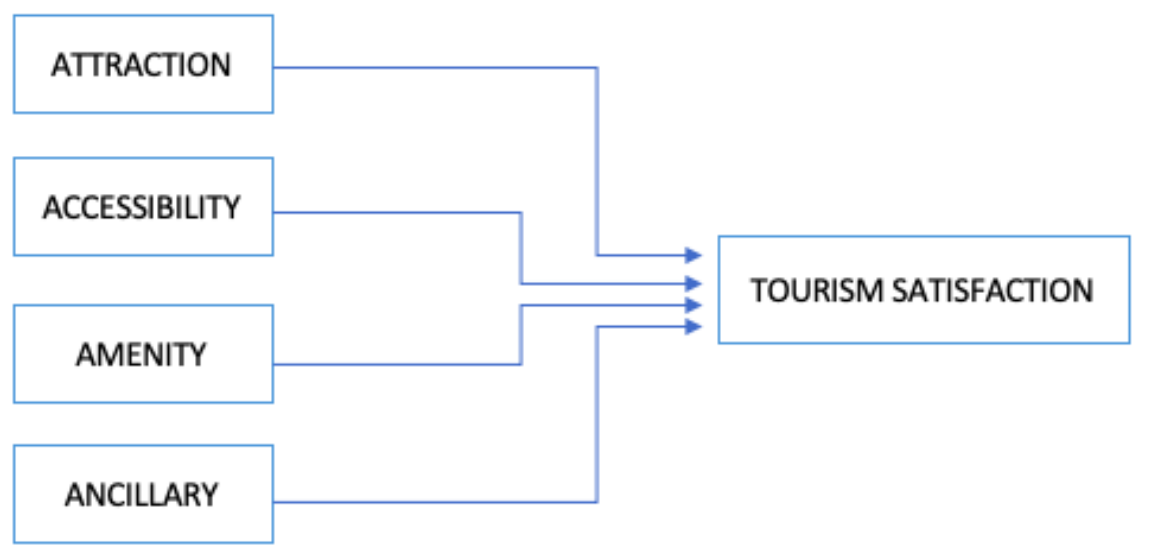

Gambar 1 : Kerangka Konseptual Penelitian Sumber : Berbagai Artikel (Diolah) 2020

\section{HASIL DAN ANALISIS}

Tabel 1 : Output Regression Results

\begin{tabular}{llccc}
\hline Independent variable & B & Beta & Tcount & Sig \\
\hline Attraction & 0.373 & 0.057 & 6.491 & 0,000 \\
Accessibility & 0.172 & 0.073 & 2.351 & 0.022 \\
Amenity & -0.101 & -0.006 & -0.084 & 0.933 \\
Ancillary & 0.333 & 0.350 & 3.676 & 0,001 \\
\hline Dependent Variabel & Tourist Satisfaction (Y) & & \\
\hline Constant & 3.939 & & \\
$\mathrm{R}$ & 0.908 & & \\
$\mathrm{R}_{2}$ & 0.825 & & \\
R2 Adjusted & 0.813 & & \\
F hitung & 64.919 & & \\
Probability & 0,000 & & &
\end{tabular}


Dapat dilihat pada tabel 1 dengan nilai signifikan $X_{1}=0,000$ dan $X_{4}=0,001$ lebih kecil dari 0,05. Bias disimpulkan, dari empat variable yang diteliti ternyata hanya dua variable yaitu X1 dn X4 yang signifikan. Variable X2 dan X3 dinyatakan tidak signifikan karena nilainya lebih besar dari alpha (5\%) atau 0,005. Kontribusi pengaruh variable yang diteliti terhadap kepuasan wisatawan sebesar 82,5\%, dan sisanya $17,5 \%$ merupakan kontribusai dari variable lain yang tidak dianalisis dalam penelitian ini. Dan nilai e1 = $\sqrt{ }(1-0,825)=0,418$.

Hasil uji f menyatakan hubungan antara variable yang diteliti dengan kepuasan wisatawan diterima berdasarkan hasil F hitung 64,919 dengan signifikasi 0,000, yang mana h0 di tolak dan h1 terima.

\section{Uji Hipotesis ke 1}

Attraction berpengaruh positif dan signifikan terhadap kepuasan wisatawan. Berdasarkan perhitungan dengan aplikasi statistik didapat jika attraction brpengaruh positif dan signifikan pada kepuasan wisatawan, sehingga persepsi dari wisatawan dapatkan dengan yang wisatawan rasakan dapat berdampak positif terhadap Wisata Kampung Topeng Tlogowaru. Dengan melihat probabilitas $<0,05$ yaitu 0,000. Hasil ini mendukung penelitian yang dilakukan (Astuti \& Noor, 2016) berdasarkan hasil penelitian mengemukakan bahwa attraction (atraksi) berpengaruh positif dan signifikan terhadap kepuasan wisatawan di Taman Safari Indonesia II Prigen Pasuruan. Dengan demikian dapat dijelaskan bahwa semakin baik dan beragamnya attraction yang ada pada Wisata Kampung Topeng maka akan semakin tinggi pula keputusan wisatawan untuk berkunjung kembali. Kepuasan wisatawan yang dimaksud antara lain dicirikan oleh: dengan ditambahkannya permainan anak yang aman untuk digunakan, penambahan suatu kegiatan wisata seperti membuat dan mewarnai topeng, belajar menari topeng malangan, dan lain-lain, penambahan kios-kios penjual cindera mata khas Wisata Kampung Topeng Tlogowaru, kios kuliner juga dapat mempengaruhi kepuasan wisatawan. Memperkuat jawaban respondent tentang attraction yang ada di Wisata Kampung Topeng Tlogowaru ditanggapi dengan jawaban setuju.

\section{Uji Hipotesis ke 2}

Accesibility berpengaruh positif dan tidak signifikan terhadap kepuasan wisatawan. Dimana hasil penelitian ini didasarkan pada hasil perhitungan dengan aplikasi statistik yang menyatakan bahwa accesibility berpengaruh positif dan tidak signifikan terhadap kepuasan wisatawan. Melihat nilai probabilitas $>0,05$ yaitu 0,022. Dengan demikian, dapat dijelaskan bahwa semakin baik dan mudah dijangkaunya accessibility atau aksesibilitas yang ada menuju kawasan Wisata Kampung Topeng Tlogowaru bukan menjadi suatu jaminan jika dapat meningkatkan kepuasan wisatawan. Hasil penelitian ini menolak temuan dari (Naiobe, 2014) berdasarkan hasil penelitiannya diperoleh hasil bahwa accesibility berpengaruh positif dan signifikan terhadap kepuasan wisatawan di Pantai Tiga Warna Malang. Dengan demikian dapat dijelaskan bahwa semakin baik dan beragamnya accesibility yang ada pada Wisata Kampung Topeng tidak menjadi jaminan jika kepuasan wisatawan akan didapat. Accesibility yang dimaksud antara lain dicirikan oleh: akses jalan beraspal, penunjuk arah yang jelas, penunjuk arah yang mudah dihami wisatawan, rute yang dilalui mudah utuk dijangkau.

\section{Uji Hipotesis ke 3}

Amenity berpengaruh negatif dan tidak signifikan terhadap kepuasan wisatawan. Dengan hasil perhitungan dari aplikasi statistik yang menyatakan jika amenity berpengaruh negatif dan tidak signifikan terhadap kepuasan wisatawan, nilai dari probabilitas > 0,05 yaitu sebesar 0,933. Menolak temuan dari (Cahyanti, 2018), dengan penelitiannya mendapatkan jika amenity berpengaruh positif dan signifikan 
terhadap kepuasan wisatawan. Sedangkan pada penelitian ini amenity berpengaruh negative dan tidak signifikan terhadap kepuasan wisatawan. Dengan demikian dapat dijelaskan bahwa amenity yang sudah ada di Wisata Kampung Topeng belum dapat meningkatkan kepuasan wisatawan. Amenity yang dimaksud antara lain dicirikan oleh: terdapatnya toilet umum bagi wisatawan yang bersih, terdapatnya mushola yang bersih dengan fasilitas mukena/sarung, terdapatnya tempat parkir yang aman untuk kendaraan wisatawan. Temuan ini diperkuat dengan hasil dari respondent yang menyatakan amenity menanggapi netral.

\section{Uji Hipotesis ke 4}

Ancillary Service berpengaruh signifikan terhadap kepuasan wisatawan. Dimana perhitungan dengan aplikasi statistik memperoleh hasil jika ancillary service berpengaruh positif dan signifikan terhadap kepuasan wisatawan. Dimana probabilitasnya $<0,05$ senilai 0,001 . Hasil penelitian ini menolak penelitian yang telah dilakukan oleh (Hirst \& Kirby, 1996) , berdasarkan hasil penelitiannya diperoleh hasil bahwa Ancillary Service berpengaruh negatif dan tidak signifikan terhadap kepuasan wisatawan di Rumah Betang Ensaid Panjang, Kabupaten Sintang. Sedangkan pada penelitian ini ancillary service berpengaruh positif dan signifikan terhadap kepuasan wisatawan. Dengan demikian dapat dijelaskan bahwa ancillary service yang ada di Wisata Kampung Topeng dapat meningkatkan kepuasan wisatawan. Ancillary Service yang dimaksud antara lain dicirikan oleh: terdapatnya petugas yang berjaga, terdapatnya pos keamanan serta terdapatnya pusat informasi wisata. Hasil ini diperkuat dari pernyataan respondent tentang Ancillary Service ditanggapi setuju.

\section{PEMBAHASAN}

Dalam mengembangkan suatu destinasi wisata sangat dibutuhkan biaya dan keberanian berinvestasi sehingga pengelola juga harus pandai-pandai membaca peluang tentang prospek wisata kampung topeng kedepan sehingga investasi yang dilakukan dapat berjalan atau berhasil dengan maksimal (Windhyastiti, Hidayatullah, \& Khouroh, 2019). Penambahan atraksi wisata contohnya diadakan suatu aktifitas wisata seperti kegiatan tari-tarian atau belajar membuat topeng, mewarnai topeng, pameran atau bazar dan sebagainya. Penambahan fasilitas wisata seperti diadakannya toko oleholeh atau toko souvenir dan penambahan toko makanan dan minuman. Meningkatkan keamanan wisatawan contohnya keamanan pada kendaraan wisatawan karena pada saat ini tidak terdapat petugas parkir baik untuk kendaraan sepeda motor atau mobil wisatawan. Meningkatkan Promosi Wisata pada sosial media, agar wisata kampung topeng lebih dikenal oleh masyarakat, dan terus berinovasi serta selalu memperbarui dan memperbaiki hal" yg sudah bagus agar lebih bagus lagi. Untuk pihak pemerintah bisa memperhatikan wisata ini, dengan membantu mempromosikan Wisata Kampung Topeng Tlogowaru pada masyarakat luas untuk dapat menyelesaikan permasalahan penurunan tingkat kunjungan di wisata ini. Dari penelitian yang sudah dilakukan didapatkan hasil bahwa variabel amenity tidak berpengaruh langsung terhadap kepuasan dan tidak berpengaruh secara tidak langsung terhadap keputusan berkunjung kembali melalui kepuasan. Artinya jika kedepannya amenity yang ada pada Wisata Kampung Topeng saat ini ditingkatkan kembali pada kebersihan, kelengkapan dan keamannya diharapkan akan dapat meningkatkan kepuasan wisatawan dan minat berkunjung kembali wisatawan.

Selanjutnya juga perlu adanya sistem informasi pemasaran untuk memasarkan kampung topeng secara maksimal (Hidayatullah et al., 2020) dengan begitu informasi yang ada akan terus terupdate dengan baik serta dengan harus memperhatikan kualitas dari informasi yang ditampilkan (Hidayatullah et al., 2020; Rakhmadian, Hidayatullah, Respati, \& Malang, 2017) seperti tatalatak informasi dalam web serta konten atau isi informasi yang menarik selain itu adanya inovasi yang terbaru dengan jiwa entrepreneurial pengelola (Abdullah, 2017; Khouroh, Sudiro, Rahayu, \& Indrawati, 2020) sehingga 
suasana yang ada di kampung topeng akan lebih kekinian. Selain itu untuk untuk menarik minat usia millennial pihak pengelola juga harus memahami keinginan dari kaum milenial dalam berkunjung ke tempat wisata (S. Alvianna \& Hidayatullah, 2020).

\section{E. SIMPULAN}

Kesimpulan dalam penelitian ini adalah Attraction berpengaruh positif dan signifikan terhadap kepuasan wisatawan, Accessibility berpengaruh positif dan tidak signifikan terhadap kepuasan wisatawan, Amenity pada Wisata Kampung Topeng Tlogowaru yang berpengaruh negatif dan tidak signifikan terhadap kepuasan wisatawan, Ancillary service berpengaruh positif dan signifikan terhadap kepuasan wisatawan.

\section{REFERENCES}

Abdullah, A. (2017). The effect of entrepreneurial marketing and competitive advantage on marketing performance. Russian Journal of Agricultural and Socio-Economic Sciences, 71(11), 212-220. https://doi.org/10.18551/rjoas.2017-11.28

Alvianna, S. (2017a). Analisis Pengaruh Harga, Produk, Dan Kualitas Layanan Terhadap Kepuasan Wisatawan Di Taman Wisata Air Wendit Kabupaten Malang. Jurnal Pariwisata Pesona, 2(1). https://doi.org/10.26905/jpp.v2i1.1263

Alvianna, S. (2017b). Peran Biro Perjalanan Wisata Sunrise Holiday Tour \& Travel Dalam Meningkatkan Minat Wisata Ke Gunung Bromo. Jurnal Pariwisata Pesona, 2(2). https://doi.org/10.26905/jpp.v2i2.1450

Alvianna, S., \& Hidayatullah, S. (2020). Pengaruh Kualitas Harga Layanan dan Kepuasan terhadap Kesetiaan Usia Millenial Berkunjung ke Tempat Wisata. Media Wisata, 18(1), 69-80. https://doi.org/10.36275/mws

Astuti, M. T., \& Noor, A. A. (2016). Daya Tarik Morotai sebagai Destinasi Wisata Sejarah dan Bahari. Jurnal Kepariwisataan Indonesia: Jurnal Penelitian Dan Pengembangan Kepariwisataan Indonesia, 11(1), 25-46.

Badan Pusat Statistik Kota Malang. (2016). Kota Malang dalam Angka. Malang: Badan Pusat Statistik Kota Malang.

Cahyanti, M. M. (2018). Pengaruh Daya Tarik Wisata Terhadap Niat Berkunjung Ulang Melalui Kepuasan Wisatawan (Studi pada wisatawan "Kampung Warna Warni" di Kota Malang). Akutansi Bisnis \& Manajemen (ABM ), 25(1), 12. https://doi.org/10.35606/jabm.v25i1.347

Garth, W. (2015). Millennials: Key to Your Future? Journal of Financial Planning, 28(11).

Hidayatullah, S., Rachmawati, I. K., Aristanto, E., Waris, A., \& Patalo, R. G. (2020). Peran Sistem Informasi Pemasaran, Kualitas Pelayanan dan Entrepreneurial marketing serta Kepuasan Terhadap Loyalitas Generasi Milenial Berkunjung ke Tempat Wisata. Jurnal Ilmiah Bisnis Dan Ekonomi Asia, 14(1), 74-83. https://doi.org/10.32812/jibeka.v14i1.184

Hidayatullah, S., Rachmawati, I. K., \& Khouroh, U. (2017). The Effectivity of "Pokdarwis" Role on Successfully Marketing of Tourism Village Towards "Mega Tourism: Batu City For The World." International Conferences SDGs 2030 Challenges and Solutions, (August), 978-979.

Hidayatullah, S., Waris, A., \& Devianti, R. C. (2018). Perilaku Generasi Milenial dalam Menggunakan Aplikasi Go-Food. Jurnal Manajemen Dan Kewirausahaan, 6(2). https://doi.org/10.26905/jmdk.v6i2.2560

Hirst, E., \& Kirby, B. (1996). Ancillary services. Proceedings of the American Power Conference. https://doi.org/10.1016/s1040-6190(98)00024-4

Khouroh, U., Sudiro, A., Rahayu, M., \& Indrawati, N. K. (2020). The mediating effect of entrepreneurial marketing in the relationship between environmental turbulence and dynamic capability with sustainable competitive advantage: An empirical study in Indonesian MSMEs. Management Science Letters, 10(3), 709-720. https://doi.org/10.5267/j.msl.2019.9.007 
Kotler, P. (1990). Marketing management and strategy: A reader. Long Range Planning, 23(6), 130. https://doi.org/10.1016/0024-6301(90)90145-T

Naiobe, Y. (2014). Malang Raya Ditarget Jadi Destinasi Wisata. Retrieved March 27, 2020, from SINDONEWS.com website: https://nasional.sindonews.com/read/925765/149/malangraya-ditarget-jadi-destinasi-wisata-1416292585

Pendit, N. S. (2002). Ilmu Pariwisata. Pariwisata.

Rakhmadian, M., Hidayatullah, S., Respati, H., \& Malang, U. M. (2017). Analisis Kualitas Sistem Dan Kualitas Informasi Terhadap Kepuasan Pemakai Sistem Informasi Akademik Dosen. Seminar Nasional Sistem Informasi, (September), 665-675.

Scott, N., Cooper, C., \& Baggio, R. (2008). Destination Networks. Annals of Tourism Research. https://doi.org/10.1016/j.annals.2007.07.004

Soebiyantoro, U. (2010). Pengaruh ketersediaan sarana prasarana, sarana transportasi terhadap kepuasan wisatawan. Jurnal Manajemen Pemasaran, 4(1). https://doi.org/10.9744/pemasaran.4.116-22

Tang, M. (2014). Tourist Attraction , Satisfaction , and Behavioral Intention of Industrial Tourist: Economic Factors as Moderator. The Journal of International Management Studies, 9(2), 105-112.

Windhyastiti, I., Hidayatullah, S., \& Khouroh, U. (2019). How to increase city investment attraction. International Journal of Scientific and Technology Research, 8(9), 1070-1073. 